\title{
Combinations of Carbapenem with Fluoroquinolones or 1,3,4 -Oxadiazole-2 -Thione Derivatives as New Broad Spectrum Bactericidal Antibiotics for Ophthalmic Preparation
}

\author{
Noor A. Waheed ${ }^{1}$, Hashim J. Azeez ${ }^{2}$, Faris T. Abachi ${ }^{1, ~ *}$ \\ ${ }^{1}$ Department of Pharmaceutical Chemistry, College of Pharmacy, University of Mosul, Mosul, Iraq \\ ${ }^{2}$ Department of Chemistry, College of Education, University of Salahddin, Erbil, Iraq
}

Email address:

farisabachi@yahoo.com (F. T. Abachi)

${ }^{*}$ Corresponding author

\section{To cite this article:}

Noor A. Waheed, Hashim J. Azeez, Faris T. Abachi. Combinations of Carbapenem with Fluoroquinolones or 1,3,4 -Oxadiazole-2 -Thione Derivatives as New Broad Spectrum Bactericidal Antibiotics for Ophthalmic Preparation. Journal of Drug Design and Medicinal Chemistry. Vol. 2, No. 5, 2016, pp. 47-50. doi: 10.11648/j.jddmc.20160205.11

Received: August 27, 2016; Accepted: October 12, 2016; Published: October 14, 2016

\begin{abstract}
The present work describes the preparation and evaluation of an ophthalmic eye drops of antibacterial agent. The active ingredients (mereopenem, fluoroquinolones \& 1,3,4 oxadiazole -2-thione derivatives) have been used in the formulation as eye drops with different doses as broad spectrum antibiotics to minimize the emergence of resistance lesion such as conjunctivitis or corneal ulcers. The experimental effectiveness of single or combination ophthalmic preparation as eye drop is well documented against different types of bacteria e.g. P.aeruginosa and other $\mathrm{G}^{(+) \mathrm{ve}} \& \mathrm{G}^{(-) v e}$ bacteria. Other parameters $\mathrm{pH}$, sterility, particulates and contents were calculated. All solutions are sterile, clear, isotonic and $\mathrm{pH}$ (5.1-6.3). These solutions didn't cause any eye irritation in rabbits after daily application for four consecutive days. The potential clinical significant of combination therapy over monotherapy for different types of bacteria has been a controversial subjects for many years especially for ophthalmic purposes. The mechanism of carbapenem and fluoroquinolones are well known, while oxadiazole derivative is expected to inhibit p-amino benzoic acid. The uses of combination drug is thought to minimize the emergence of resistance, safe, potent and increase their synergistic activities.
\end{abstract}

Keywords: Carbapenem, Ciprofloxacin, Olfloxacin, Moxifloxacin, Conjunctivitis, Corneal Ulcers

\section{Introduction}

Recent efforts towards combating antibiotic resistance in bacteria have focused on on $\mathrm{G}^{+\mathrm{ve}}$ bacteria; however, multidrug-resistant $\mathrm{G}^{\text {-ve }}$ bacteria pose a significant risk to public health. An orthogonal approach to the development of new antibiotics is to develop adjuvant compound that enhance the susceptibility of drug - resistant strains of bacteria to currently approved antibiotic [1].

Three different synthetic antimicrobial agents were prepared as a septic solution in different concentrations. The first antibiotic is Meropenem trihydate (Figure 1), is a carbapenem antibiotic that is commonly used to treat a variety of pathogens in critically patients.

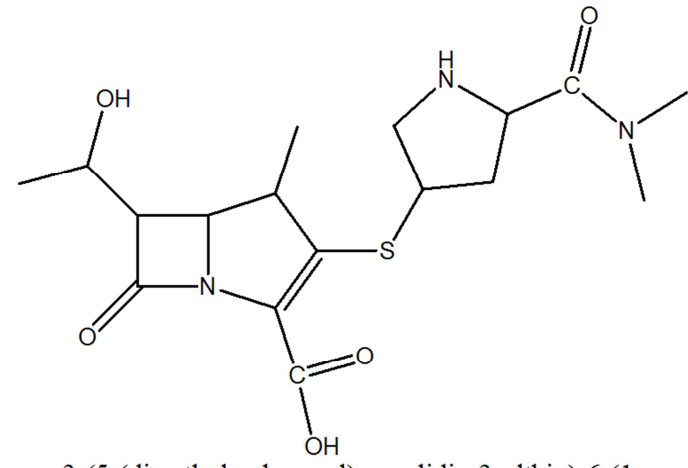

3-(5-(dimethylcarbamoyl)pyrrolidin-3-ylthio)-6-(1hydroxyethyl)-4-methyl-7-oxo-1-aza-bicyclo[3.2.0]hept-2ene-2-carboxylic acid

Figure 1. Chemical structure of Meropenem. 
The second antibiotic is fluoroquinolone derivative from quinolone (Nalidixic acid), (such as Ciprofloxacin, Ofloxacin $\&$ Moxifloxacin) (Figure 2). The first fluoroquinolones were widely used because they were the only orally administered agents available for the treatment of serious infections caused by gram-negative organisms, including Pseudomonas species [2].

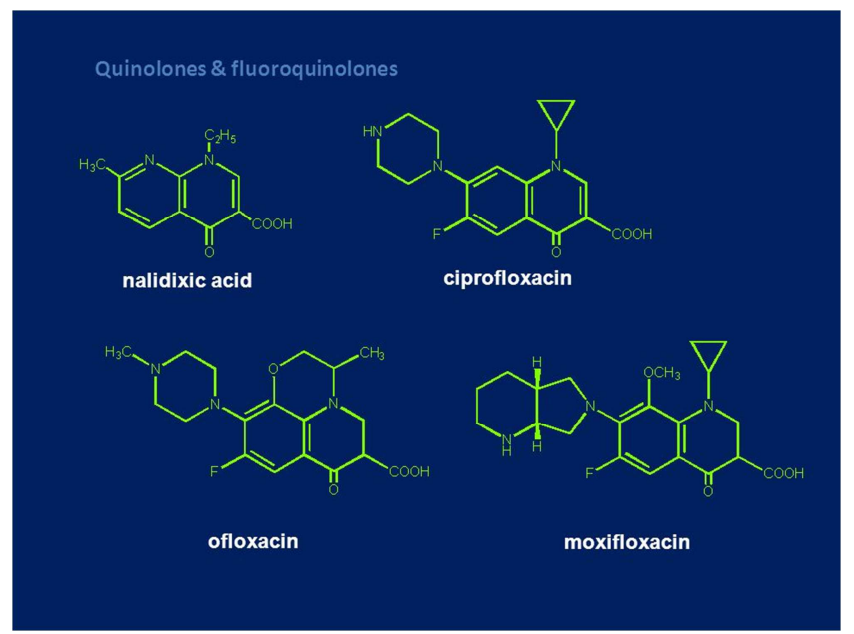

Figure 2. Chemical structures of Quinolone \&Fluoroquinolone.

The third synthetic antimicrobial agent is $1,3,4$ Oxadiazole 2-thione derivative (Figure 3) [3].

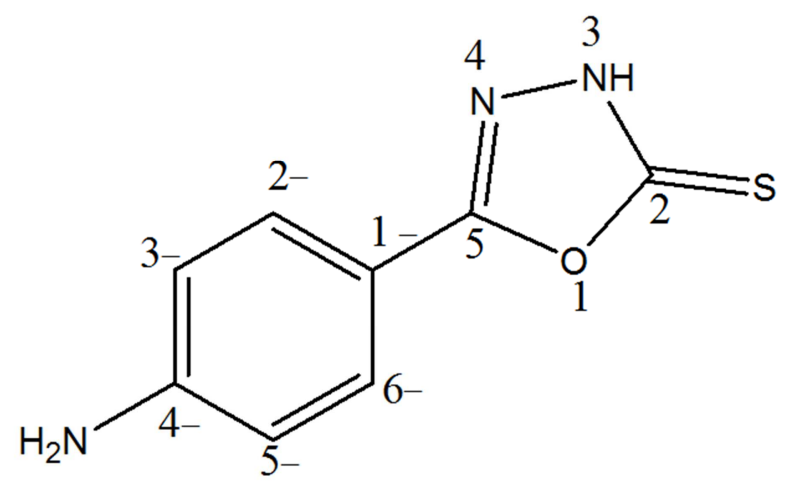

Figure 3. Chemical structure of 1,3,4 Oxadiazole-2-thione derivative.

The ophthalmic mixed solution were prepared in different dosses and concentration and test their antibacterial activity as novel combination therapy $[4,5]$.

\section{Experimental}

\subsection{Chemistry}

Meropenem trihydrate (ACS Dobfar SPA, Italy), Fluoroquinolones (Solarbio life sciences, China), paminobenzoic acid (Fluka), water for injection (USP).

\subsection{General}

Melting point determination: The melting point of an organic compound was determined by melting point tube (capillary tube method). The determination of melting point is the most important and easy way of differentiating this physical constant of one compound from other. Thin layer chromatography (TLC): TLC is an important method for synthetic chemistry to infer the formation of compound based on the $\mathrm{R}_{\mathrm{f}}$ value since different compound will have different $\mathrm{R}_{\mathrm{f}}$ values. (Solvent ratio). It also helps in confirming the progress of the reaction. Fourier Transform Infrared (FT-IR): is the most important tools for determining the various functional group and the possible chemical structure. The important advantage of FT-IR over other technique is that it gives fingerprints (3300-650 cm-1) information about the structure (functional group, bonding with each other) of molecules easily, no two compounds have identical fingerprint region. This technique is based upon the molecular vibration of the compound such that each and every bond will vibrate at the different frequency. FTIR spectra were recorded in $\mathrm{KBr}$ powder on a SHIMADZU FTIR spectrometer. Both ${ }^{1} \mathrm{H} \&{ }^{13} \mathrm{C}$ NMR were recorded in $\mathrm{CDCl}_{3} \&$ DMSO on a Bruker $300 \mathrm{MHz}$. Chemical shifts are reported in parts per million from low to high field and referenced to residual solvent. Standard abbreviations indicating multiplicity are used as follows: br $\mathrm{s}=$ broad singlet, $\mathrm{d}=$ doublet, $\mathrm{m}=$ multiplet, $\mathrm{s}=$ singlet, and $\mathrm{t}=$ triplet . In all cases $\mathrm{CDCl}_{3}$ or d-DMSO were used as the solvents, $\mathrm{D}_{2} \mathrm{O}$ may be added in order to identify $\mathrm{OH}$ or $\mathrm{NH}$ groups.

\subsection{Preparation of the 4-ethylaminobenzoate (Benzocaine) [6]}

A (0.01 mole, $1.37 \mathrm{~g})$ of p-aminobenzoic acid (PABA) was dissolved in $15 \mathrm{ml}$ of absolute ethanol before $\operatorname{adding}(0.01$ mole, $1.1 \mathrm{ml}$ ) of thionyl chloride drop by drop, the mixture was reflux for $2 \mathrm{~h}$ in hood, the excess of thionyl chloride was evaporated and the was cooled in ice bath, the precipitate was filtered and recrystallized by ethanol to give off white crystals as salt, yield $98 \%$, m. p : $197-200^{\circ} \mathrm{C}$. The product was treated with $5 \%$ sodium bicarbonate, mix it vigorously and extract with chloroform, dry the organic layer with magnesium sulphate, filter and evaporate the chloroform layer to dryness, to obtain the free ester product. m. p.; 79$82^{\circ} \mathrm{C}$. (Reported $89-90^{\circ} \mathrm{C}$ ).

\subsection{Preparation of 4-aminobenzoylhydrazide [6]}

A (0.01 mole, $1.65 \mathrm{~g})$ of p-aminoethylbenzoate was mixed with $7 \mathrm{ml}$ of hydrazine hydrate $80 \%$, the mixture was reflux for $5 \mathrm{~h}$, the white precipitate was filtered and recrystallized by distilled water to give white crystals, yield $97.2 \%$, m. p.: 220 $222^{\circ} \mathrm{C}$.

\subsection{Preparation of 5-(4-aminophenyl)-1,3,4-oxadiazole-2- Thione [6]}

A mixture of $(0.01$ mole, 1.51g), 4aminobenzoylhydrazide with a mixture of ( 0.01 mole, $0.56 \mathrm{~g}$ of $\mathrm{KOH}$ in $16 \mathrm{ml}$ of ethanol), then add 0.01 mole $0.6 \mathrm{~g}$ of carbon disulphide was refluxed with stirring for $20 \mathrm{~h}$. The contents were poured into ice cold water and acidified with dil. $\mathrm{HCl}$ to give the desired product which was recrystallized 
from ethanol. The percentage yield: $98 \%$, m. p. $250-252^{\circ} \mathrm{C}$. $\mathrm{R}_{\mathrm{f}} ; 0.88$. (Solvent: Solvent).

Weigh $3 \mathrm{mg}$ or $5 \mathrm{mg}$ of the corresponding antibiotic, dissolve in water for injection, mixed well with stainless steel mixer for 5 minutes, filter with $0.45 \mu$ filter paper, then put into autoclave $\left(116^{\circ} \mathrm{C}\right.$ temperature, 0.75 Bar pressure for 40minutes. Five monotherapy solution were tested their activities against different $\mathrm{G}(+)$ ve and $\mathrm{G}(-)$ ve bacterial activities, and compare their activities with new combination of menopenem $(5 \mathrm{mg} / \mathrm{ml})$ with fluoroquinolones (Ciprofloxacin, Olfoxacin, Moxifloxacin) $0.3 \mathrm{mg} / \mathrm{ml}$ or new synthetic oxadiazole-2-thione $0.3 \mathrm{mg} / \mathrm{ml}$. This formulation of eye drops in table 1, are thought to minimize the emergence of resistance lesion such as conjunctivitis or corneal ulcers [7].

Table 1. Some physical properties of the Ophthalmic preparations.

\begin{tabular}{ll}
\hline Test & Preparation Results \\
Appearance & Colorless clear solution \\
Content & $100 \%$ \\
$\mathrm{pH}$ & $6.1-6.3$ \\
Isotonicity & Isotonic (Corrected with NaCl solution) (USP). \\
Pyrogene & Sterile (USP). \\
Sterility & (-)ve bacteria (Sterile solution)(USP). \\
Particulate matter & No particulate (USP). \\
Eye of Rabbit & No irritation (four days). \\
\hline
\end{tabular}

\subsection{Microbiology $[8]$}

All the newly synthesized compounds were evaluated for in vitro antibacterial activity against gram positive and gram negative bacterial strains such as Staphylococcus aureus, Escherichia coli and Pseudomonas aureginosa at concentration $100 \mu \mathrm{g} / \mathrm{mL}$ by disc diffusion method by using DMSO as solvent control and nutrient agar was employed as culture media. After $24 \mathrm{~h}$ of incubation at $37^{\circ} \mathrm{C}$, the zone of inhibition was measured in $\mathrm{mm}$. The activity was compared with known antibiotic Cefotaxime and the date was represented in table 2 .

Table 2. Screening for antibacterial activity.

\begin{tabular}{|c|c|c|c|c|c|}
\hline \multicolumn{6}{|c|}{ Inhibition Zone (mm) } \\
\hline Compounds & pH & S.auresu & E.coli & P.aregenosia & Notes \\
\hline $\begin{array}{l}\text { 1-Meropenem } \\
5 \mathrm{mg} / \mathrm{ml}\end{array}$ & 5.7 & 37 & 35 & 18 & +++ \\
\hline $\begin{array}{l}\text { 2- Ofloxacin } 0.3 \\
\mathrm{mg} / \mathrm{ml}\end{array}$ & 6.2 & 20 & 35 & 25 & +++ \\
\hline $\begin{array}{l}\text { 3-Ciprofloxacin } \\
0.3 \mathrm{mg} / \mathrm{ml}\end{array}$ & 6.2 & 7.5 & 15 & 10 & ++ \\
\hline $\begin{array}{l}\text { 4- Moxifloxacin } \\
0.3 \mathrm{mg} / \mathrm{ml} \\
45-\end{array}$ & 6.1 & 25 & 35 & 27 & +++ \\
\hline $\begin{array}{l}\text { 1,3,4Oxadiaxzole- } \\
\text { 2-thione }\end{array}$ & 5.2 & 0 & 0 & 1 & $\mathrm{~N}+-$ \\
\hline $1 \& 3$ & 6 & 42.5 & 35 & Not Done & + \\
\hline $1 \& 2$ & 6.1 & 37.5 & 34 & Note Done & + \\
\hline $1 \& 4$ & 6 & 43 & 35 & Not Done & + \\
\hline $1 \& 5$ & 5.1 & 37 & 40 & Not Done & ++ \\
\hline Cefotaxim & 5.3 & 10 & 25 & 0 & Reference \\
\hline
\end{tabular}

$(+)$ Slightly Active, $(++)$ active, $(+++)$ highly active (Broad spectrum antibacterial agent).(-) Not significant.

\section{Results \& Discussion}

The synthetic 1,3,4 Oxadiazole -2-thione derivative as new heterocyclic compound according to the scheme 1 .

Esterification of $\mathrm{p}$-aminobenzoic acid (PABA) with thionyl chloride and abs. ethyl alcohol under reflux to yield ethyl 4aminobenzoate.

The FT-IR spectrum of compound, show the $v_{\mathrm{cm}-1}(\mathrm{KBr}$ disc): 3221 for N-H stretching, 2985\&2729 for aliphatic C-H stretching aromatic \& aliphatic, 1724 for $\mathrm{C}=\mathrm{O}$ group of ester, 1612 for N-H bending.

${ }^{1} \mathrm{H}-\mathrm{NMR}$ ( $\delta$, ppm) (DMSO-d6), show the following signals: $1.15-1.43(\mathrm{t}, 3 \mathrm{H}) \mathrm{CH}_{3}, 2.32-2.62$ (q, $\left.2 \mathrm{H}\right) \mathrm{CH}_{2}, 7.45-$ $7.82(\mathrm{dd}, 4 \mathrm{H}) \mathrm{ph}, 6.75(\mathrm{~m}, 2 \mathrm{H}) \mathrm{NH}_{2} \cdot{ }^{13} \mathrm{C}-\mathrm{NMR}(\delta, \mathrm{ppm})$ (DMSO-d6), show the following signals: $9.65 \mathrm{C1}\left(\mathrm{CH}_{3}\right)$, $45.47 \quad \mathrm{C} 2\left(\mathrm{CH}_{2}\right), \quad 171.14 \quad \mathrm{C} 3 \quad(\mathrm{C}=\mathrm{O}), \quad 151.72 \quad \mathrm{C} 9(\mathrm{C}-$ $\mathrm{NH}_{2}$ ), 119.1C7 \& C8 (Aromatic), 121.4 C5 \& C6 (Aromatic).

The hydrazide derivative was achieved by reaction of the ester with appropriate hydrazide hydrate in abs. ethanol as a solvent. The FT-IR $v_{\mathrm{cm}-1}(\mathrm{KBr}$ disc) show the following characteristic bands:3307 \& $3230 \quad(\mathrm{~N}-\mathrm{H})$ stretching of aromatic \& aliphatic, $1633(\mathrm{C}=\mathrm{O})$ amide, 1584 (C-H) bending.

${ }^{1} \mathrm{H}-\mathrm{NMR} \quad(\delta, \mathrm{ppm})$ (DMSO-d6) show the following signals: $5.57(\mathrm{~m}, 5 \mathrm{H}) \mathrm{NH}, 7.52-7.54(\mathrm{dd}, 4 \mathrm{H})$ ph psubstituted aromatic ring. ${ }^{13} \mathrm{C}-\mathrm{NMR}(\delta, \mathrm{ppm})$ (DMSO-d6) show the following peaks: $166.42 \mathrm{C} 1(\mathrm{C}=\mathrm{O}), 151.48 \mathrm{C} 7(\mathrm{C}-$ $\mathrm{NH}_{2}$ ), $112.73 \mathrm{C} 3$ \& C4 (ph), 119.94 C5 \& C6 (ph).

Cyclization of oxadiazole was takes place via condensation of hydrazide with $\mathrm{KOH}$ and $\mathrm{CS}_{2}$ in ethanol.

The characteristic bands $\mathrm{v} \mathrm{cm}^{-1}(\mathrm{KBr}$ disc): $3394(\mathrm{NH})$ stretching, 3315 (NH)cyclic, 3045.6, 2924.09 for $\mathrm{C}-\mathrm{H}$ stretching Aromatic \& Aliphatic respectively, $1606.7(\mathrm{C}=\mathrm{N})$ imine, 1479, 1346 for $(\mathrm{C}-\mathrm{N})$ bending $\& 1068(\mathrm{C}=\mathrm{S})$. The thiol (S-H) and thione $(\mathrm{C}=\mathrm{S})$ are in equilibrium with the tautomeric oxadiazole.

${ }^{1} \mathrm{H}-\mathrm{NMR}(\delta, \mathrm{ppm})$ (DMSO-d6): 3.93 solvent, 5.41(m, 3H) for $\mathrm{N}-\mathrm{H}, 8.08-8.88(\mathrm{dd}, 4 \mathrm{H})$ for para substituted aromatic ring. $\mathrm{D}_{2} \mathrm{O}$ was added to identify the $\mathrm{N}-\mathrm{H}$ proton, after addition and mix the NMR tube and measure again for the sample, new peak 3.76 ppm strong peak for HOD, give a good evidence for proton exchange.

Antimicrobial is an agent that kills microorganisms or inhibit their growth and are used to microbial infections. Antimicrobial agents can be classified according to their mechanisms they act primarily against.

Meropenem is non-classical $\beta$ - lactam synthetic antibiotic (Carbapenem), fluoroquinolones (Ciprofloxacin, Ofloxacin, Moxifloxacin) are belong to second and third generation fluoroquinolones and are play an important role as new and effective antibacterial agents for treatment of infectious diseases. Both meropenem and fluoroquinolones are broad spectrum antibiotic, the novel synthetic analogs of meropenem, fluoroquionlones and 1,3,4- oxadiazole of paminobenzoic derivative were tested their antimicrobial activities in two different techniques.

Disc diffusion in agar is a common method of testing the 
sensitivity of bacteria to antibiotics. A microorganism is judged sensitive or resistance according to their diameter of the zone of inhibition the bacterial growth, which is then correlated statistically with the minimal inhibitory concentration (MIC) $[9,10]$.

The advantages of disc method are the test simplicity, the provision of categorical results easily interpreted by all researchers, and flexibility formation of disc for testing. On the other hands, the primary disadvantage of disc diffusion susceptibility is that gives mainly qualitative results [9].

In the present work, the antimicrobial activity was studied as monotherapy or combination therapy and their screening results were listed in Table 2 . The screening of antibacterial activity of Moxifloxacin \& Meropenem reveals that they were the highest activity among the newly synthesized compounds in this study against one $\mathrm{G}^{+\mathrm{ve}}$ S.aureus and two of $\mathrm{G}^{-\mathrm{ve}}$ E.coli \& P.aurgenosa with different mechanism of action. Cefotaxime were used as standard antibiotics.

Only two products are highly effective as antibacterial activity as broad spectrum for both $\mathrm{G}^{(+) \mathrm{ve}} \& \mathrm{G}^{(-) \mathrm{ve}}$, and safe solution for eye as new eye drop. These solutions didn't cause any eye irritation in rabbits after daily application for four consecutive days. Further studies should be done to clarify the mechanism of action and study their toxicities.

\section{References}

[1] Christopher M. Brackett, Roberta J. Melander, Il Hwan An, Aparna Krishnamurthy, Richele J. Thompson, John Cavanagh, and Christian Melander (2014). Small-Molecule Suppression of $\beta$-Lactam Resistance in Multidrug-Resistant GramNegative Pathogens. J. Med. Chem., 57 (17), pp 7450-7458.

[2] Jin-Woong Kim, Hyeong Beom Park, Bong Young Chung,
Jong Baek Lee, Jung-Hyuck Cho, and Chang-Hyun Oh (2006). Synthesis and Antibacterial Activity of $1 \beta$-Methyl-2[5-( $\alpha, \beta$-disubstituted ethyl) pyrrolidin-3-ylthio] carbapenem Derivatives. Part II. Bull. Korean Chem. Soc., Vol. 27, No. 8.

[3] Nagaraj; Chaluvaraju, K. C.; Niranjan, M. S.; Kiran, S. (2011). 1,3,4-Oxadiazole: A potent drug candidate with various pharmacological activities. Int. J. Pharm. Pharm. Sci., $3,9-16$.

[4] Amir M; Javed SA; Kumar H. (2007). Synthesis of some 1,3,4oxadiazole derivatives as potential anti-inflammatory agents. Indian J Chem. 46B: 1014-9.

[5] Krisztina M. Papp-Wallace; Andrea Endimiani; Magdalena A. Taracila; and Robert A. Bonomo. (2011). Carbapenems: Past, Present, and Future. Antimicrobial agents \& Chemotherapy., 55 (11): 4943-4960.

[6] Franski R. (2005). Biological activities of the compounds bearing 1,3,4-oxa(thia) diazole ring. Asian J Chem. 17:206375 .

[7] Moshirfar M; Chew J; Werner L; Meyer J. J; Hunter B; Stevens S; Jensen M; Kleinmann G; Mamalis N. (2008). Comparison of the effects of fourth-generation fluoroquinolones on corneal re-epithelialization in rabbit eyes: Graefes Arch. Clin. Exp. Ophthalmol.. 246(10): 1455-61.

[8] Plech, T.; Wujec, M.; Kosikowska, U.; Malm, A.; Rajtar, B.; Polz-Dacewicz, M. (2013). Synthesis and in vitro activity of 1,2,4-triazole-ciprofloxacin hybrids against drug-susceptible and drug-resistant bacteria. Eur. J. Med. Chem. 60: 128-134.

[9] K. Drlica; M. Malik; R. J. Kerns and X. Zhao. (2008). "Quinolone mediated bacterial death. Antimicrobial Agents and Chemotherapy, 52 (2): 385-392.

[10] Tomoo SAGA; Keizo YAMAGUCHI. (2009). History of Antimicrobial Agents and Resistant Bacteria. JMAJ. 52(2): 103-108. 